\title{
Anorgasmia, CTCAE
}

National Cancer Institute

\section{Source}

National Cancer Institute. Anorgasmia, CT CAE. NCI Thesaurus. Code C143287.

A disorder characterized by an inability to achieve orgasm. 